\title{
Removal of organic compounds from waste streams: a combined approach
}

\author{
J. O’Brien, T. Curtin \& T. F. O’Dwyer \\ Chemical and Environmental Sciences Department, \\ Materials and Surface Science Institute, University of Limerick, Ireland
}

\begin{abstract}
A combination of factors, including costs associated with wastewater treatment and more restrictive and stringent controls on industrial effluent pollution have increased interest in water usage reduction, recycling and re-use opportunities. In this study a novel two-step approach to treatment of low concentrations of organic compounds in waste streams was investigated. Zeolite ZSM-5 was investigated with a view to examining its potential to function as both adsorbent and catalyst in the removal of aniline from aqueous solutions. The H-ZSM-5 zeolite was first loaded with copper before the aniline adsorption step. The aqueous stability of the exchanged copper on the zeolite was assessed as a function of solution $\mathrm{pH}$. Minimum copper leaching was observed in the range $\mathrm{pH} 5$ to $\mathrm{pH} 11$ thus providing a stable working $\mathrm{pH}$ range for the $1.4 \mathrm{Cu}-\mathrm{ZSM}-5$ to function as an adsorbent material. Aniline adsorption was then carried out and an uptake level of $40 \mathrm{mg} \mathrm{g}^{-1}$ aniline on the $1.4 \mathrm{Cu}-\mathrm{ZSM}-5$ zeolite was achieved. The adsorption process followed the Langmuir model and aniline uptake was largely uninfluenced by temperature. The kinetics of the adsorption process indicated that maximum uptake of aniline occurred within thirty minutes. In the second step of the process, the aniline loaded Cu-ZSM-5 adsorbent samples were subjected to a catalytic oxidation process and mass spectroscopic analysis of the catalytic reactor exhaust gases suggested clear oxidation of the aniline to carbon dioxide, water and nitrogen, with minor amounts of nitrogen oxide gases being produced.
\end{abstract}

Keywords: organics, ZSM-5, adsorption, catalytic oxidation, waste stream treatment. 


\section{Introduction}

Water plays an integral role in both domestic and industrial life. The UN estimates that by the middle of this century, at best, 2 billion people in forty eight countries will experience water scarcity, i.e. their annual fresh water resources will be less than $1000 \mathrm{~m}^{3}$ per capita per year. At worst, 7 billion people in sixty countries will experience severe water shortage [1]. In industry, new, innovative and cost-effective technologies are necessary to develop the recycling and reuse potential of industrial process waste streams. Examples of industries with significant water usage and potential for treatment and recycling include the pharmaceutical, refining, food and beverage, chemical, petrochemical, pulp and paper and electronics sectors [2]. In general the reduction of wastewater in any given industry can be achieved in a number of ways including process modification, changes in raw materials used or water consumption reduction programmes $[3,4]$. In practice, significant waste stream volumes are produced and where feasible the recycling and regeneration of these streams is of significant environmental and economic benefit.

A number of well-established technologies exist for waste stream treatment and recycling, including reverse osmosis (RO), micro filtration (MF) and ultra filtration (UF) $[2,5]$. Alternatives for treating waste streams containing organic type impurities include specific oxidation methods which can be divided into the following categories: chemical oxidation and air/oxygen based catalytic (or noncatalytic) oxidation. The former category includes advanced oxidation processes (AOPs). Typical AOPs use ozone, hydrogen peroxide and UV radiation to generate hydroxyl radicals used for oxidation [6]. However, these processes tend to be limited by their intensive costs. The latter category includes dry oxidation, wet air oxidation and catalytic wet air oxidation.

Currently, there is a strong interest in developing alternative adsorbents for the removal of organic pollutants from aqueous waste streams. Zeolites are one type of alternative adsorbent material and have the ability to selectively adsorb or reject molecules based upon molecular size, shape and other properties including polarity. To date, limited studies have been carried out on zeolite adsorption of organic molecules from aqueous solutions [7-9]. Zeolites also have the ability to function as catalysts. In this work ZSM-5 zeolite is loaded with copper to promote and enhance its catalytic activity. Copper exchanged zeolites have been shown to be extremely active for the catalytic oxidation of ammonia, to nitrogen and water with low levels of $\mathrm{NO}$ and $\mathrm{N}_{2} \mathrm{O}$ formed [10]. Centi and Perathoner [11] studied the adsorption and subsequent wet and dry oxidation of low levels of sodium gluconate and triethanolamine onto a series of mixed oxides. Our present work sets out to build on this knowledge.

The aqueous contaminant of interest (aniline) is chosen as the test compound as it is a nitrogen-containing hydrocarbon typical of compounds occurring in waste streams from dye, pigments, pharmaceuticals, rubber additives and pesticides manufacture. It will firstly be removed by adsorption onto a selective adsorbent Cu-ZSM-5 zeolite and, secondly, oxidation of the adsorbed pollutant 
into carbon dioxide, water and nitrogen with the simultaneous regeneration of the adsorbent/catalyst will be carried out (figure 1).

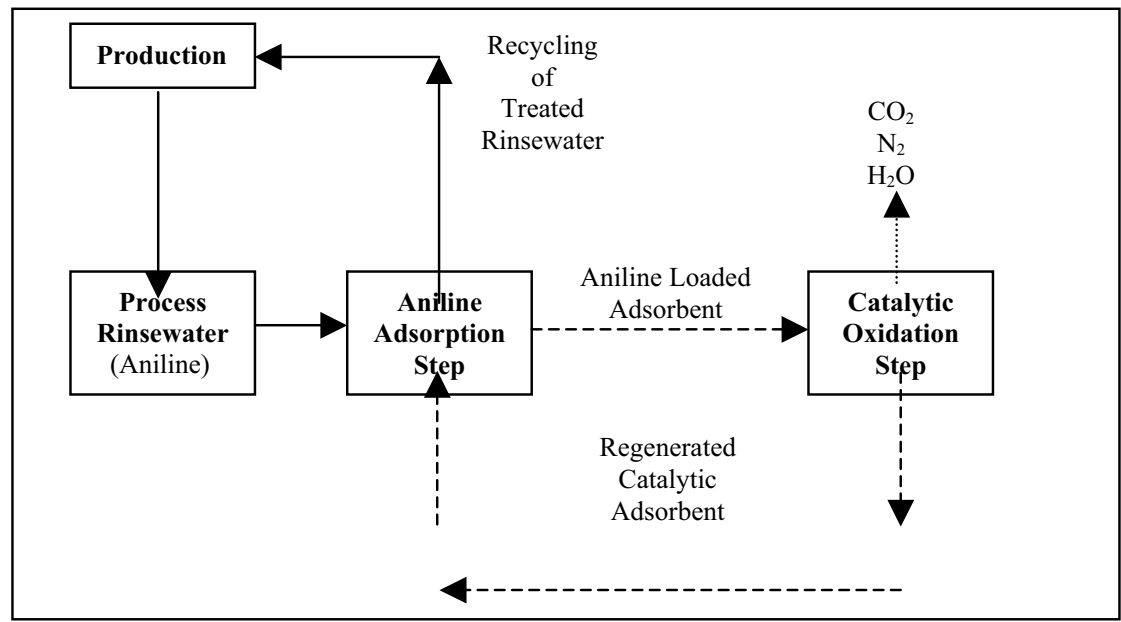

Figure 1: Adsorption/catalytic process schematic for treating and recycling waste streams.

\section{Methodology}

\subsection{Materials and zeolite characterisation}

Copper exchanged ZSM-5 zeolites were prepared using a one step procedure similar to that reported by Iwamoto et al. [12]. Briefly, the appropriate amount of copper nitrate trihydrate (Aldrich) was dissolved in water and the zeolite $\left(\mathrm{SiO}_{2}: \mathrm{Al}_{2} \mathrm{O}_{3}=80: 1\right)$ added to the aqueous salt solution. The suspension was stirred for 24 hours at room temperature and adjusted to $\mathrm{pH} 7.0$ with a $\mathrm{NH}_{4} \mathrm{OH}$ solution. The sample was filtered and dried at $80^{\circ} \mathrm{C}$ for 10 hours, calcined at $450^{\circ} \mathrm{C}$ for 5 hours and sieved to a particle size range of $212-850 \mu \mathrm{m}$. A $1.4 \mathrm{Cu}-$ ZSM-5 indicates a zeolite containing $1.4 \mathrm{wt} \%$ copper (measured by AA) on the ZSM-5 zeolite support prepared by ion exchange. Typically, $0.1 \mathrm{~g}$ of the copper exchanged zeolite was dissolved in $3 \mathrm{mls}$ of hydrofluoric acid and diluted for AAS analysis. The samples were characterized by nitrogen gas adsorption/desorption isotherms using a Micromeritics Gemini ASAP 2010 system. Samples were pretreated at $150^{\circ} \mathrm{C}$ for 17 hours and zeolite surface areas were measured using the Brunauer-Emmett-Teller (BET) method [13]. The zeolites were also characterised by X-ray diffraction using a Philips X'pert PRO MPD (multi purpose diffractometer) X-ray diffractometer PW3050/60 $\theta-\theta$ with a scan range of $5-60^{\circ}(2 \theta)$ using nickel filtered $\mathrm{Cu} \mathrm{K} \alpha$ radiation $(\lambda=1.542 \AA)$ at $40 \mathrm{kV}$ with a current of $35 \mathrm{~mA}$. 


\subsection{Copper leachability testing}

The influence of aqueous solution $\mathrm{pH}$ on the possible leaching of the copper exchanged onto the ZSM-5 support was evaluated for solutions with initial $\mathrm{pH}$ between $\mathrm{pH} 1$ and $\mathrm{pH} 11$. Specifically, the $\mathrm{pH}$ of $150 \mathrm{ml}$ distilled water was adjusted appropriately using either $\mathrm{HCl}$ or ammonia solution $\left(35 \% \mathrm{NH}_{3}\right)$ and $0.5 \mathrm{~g}$ of the copper exchanged adsorbent material was added to the solution. The solution was stirred continuously and samples were periodically withdrawn, vacuum filtered, centrifuged at 3,500 rpm and analysed by AAS.

\subsection{Adsorption isotherms}

An adsorption isotherm was prepared for aniline adsorption onto the $1.4 \mathrm{Cu}$ ZSM-5 at $6^{\circ} \mathrm{C}$ and $24^{\circ} \mathrm{C}$ using a batch technique. The adsorbent, $(0.1 \mathrm{~g})$, was allowed to reach equilibrium with aniline solutions $(10 \mathrm{ml})$ of known concentrations (50 and $4000 \mathrm{mg} \mathrm{dm}^{-3}$ ). The solutions were stirred for one hour. The contents of each adsorption flask were then separated by centrifugation at $3,500 \mathrm{rpm}$ for $20 \mathrm{~min}$ and filtered under vacuum. Pre and post-adsorption concentrations of aniline were determined by a Cary UV-Visible spectrometer $\left(\lambda_{\max } 230 \mathrm{~nm}\right)$ and the amount adsorbed was calculated by the difference.

\subsection{Catalytic oxidation experiments}

The aniline loaded adsorbent/catalyst $(100 \mathrm{mg})$ was placed in the quartz reactor and held in place by quartz wool plugs (figure 2). Before testing, the spent adsorbent sample was pre-treated for 60 minutes in a stream of a 3\% oxygenhelium mixture at a flow rate of $50 \mathrm{ml} / \mathrm{min}$. The sample was then subjected to a temperature increase of $10^{\circ} \mathrm{C} / \mathrm{min}$ up to $750^{\circ} \mathrm{C}$. Products leaving the reactor in the exhaust gases were continuously monitored using the Mass Selective Detector (MSD).

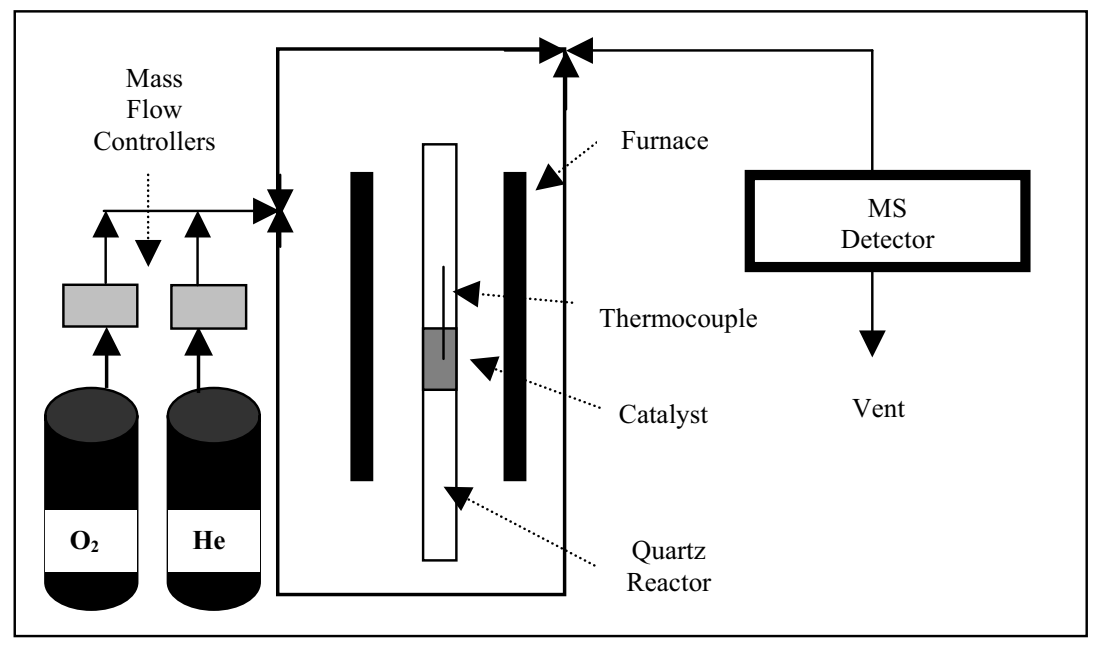

Figure 2: Catalytic oxidation setup. 


\section{Results and discussion}

\subsection{Characterization}

In this study, the actual copper loading on the zeolite was $1.4 \mathrm{wt} \%$, which corresponded to an ion-exchange level of $108 \%$. This exchange level was based on the assumption that a single $\mathrm{Cu}^{2+}$ charge balanced a pair of negatively charged aluminium sites on the zeolite framework. The X-ray diffraction patterns of the copper-exchanged zeolite was identical to that of the parent zeolite indicating good dispersion of the copper on the catalyst and the absence of any crystalline copper phase. The surface area of the copper-exchanged ZSM-5 zeolite adsorbent was estimated to be $223 \mathrm{~m}^{2} \mathrm{~g}^{-1}$ as compared to $275 \mathrm{~m}^{2} \mathrm{~g}^{-1}$ for the unmodified H-ZSM-5.

\subsection{Stability of the copper loaded ZSM-5 zeolite}

Leaching tests were undertaken on the $1.4 \mathrm{Cu}-\mathrm{ZSM}-5$ sample in order to assess the extent of copper leaching as a function of aqueous $\mathrm{pH}$. The results of this study are summarized in Table 1. From these results it is clear that the $1.4 \mathrm{Cu}-$ ZSM-5 material was most stable over the range $\mathrm{pH} 5$ to $\mathrm{pH} 9$, where the leached copper levels were less than $1 \mathrm{mg} \mathrm{dm}^{-3}$. Complete copper leaching was calculated to give a resultant aqueous concentration of $46 \mathrm{mg} \mathrm{dm}^{-3}$. At the acidic $\mathrm{pH}$ 's copper leaching was rapid and in all cases maximum leaching occurred in less than 30 minutes. A study into successive copper leaching on the $1.4 \mathrm{Cu}$ ZSM-5 samples showed that no subsequent leaching occurs after initial leaching. Therefore, the 1.4Cu-ZSM-5 zeolite can be used as a stable adsorbent material in the aqueous phase for the purposes of this work.

Table 1: $\quad$ Leaching tests on $1.4 \mathrm{Cu}-\mathrm{ZSM}-5$ ( $\mathrm{pH}$ range $1-11$ ).

\begin{tabular}{|c|c|c|c|c|c|c|}
\hline & \multicolumn{6}{|c|}{ 1.4Cu-ZSM-5 } \\
\hline $\mathrm{pH}$ & 1 & 3 & 5 & 7 & 9 & 11 \\
\hline Copper Leached (\%) & 80 & 21.4 & 0.3 & $<0.1$ & $<0.1$ & 1.5 \\
\hline Aqueous $\mathrm{Cu}^{2+}\left(\mathrm{mg} \mathrm{dm}^{-3}\right)$ & 37 & 9.8 & 0.14 & $<0.1$ & $<0.1$ & 0.7 \\
\hline Maximum Leaching (mins) & $<20$ & $<20$ & N/A & N/A & N/A & $<20$ \\
\hline
\end{tabular}

\subsection{Adsorption capacity of 1.4Cu-ZSM-5 for aniline}

A preliminary test to establish the time to reach maximum adsorption revealed maximum uptake of aniline within 30-40 minutes of contact with the adsorbent material. The adsorption isotherms for aniline on $1.4 \mathrm{Cu}-\mathrm{ZSM}-5$ at $6^{\circ} \mathrm{C}$ and $24^{\circ} \mathrm{C}$ are displayed in Figure 3. All samples show maximum aniline adsorption of between $37-42 \mathrm{mg} \mathrm{g}^{-1}$ suggesting that at this level the zeolite is saturated. This significant level of uptake indicates that the pore diameters of the ZSM-5 zeolite facilitate removal of significant quantities of aniline from an aqueous environment. The level of aniline adsorbed onto the zeolite support was largely unaffected by a change in temperature. 


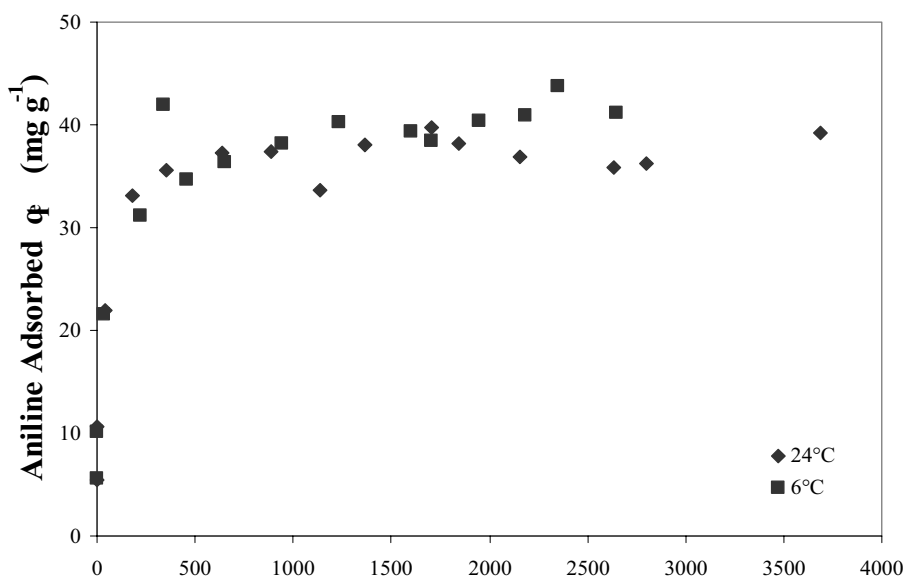

Equilibrium Aniline Concentration $\mathrm{C}_{\mathrm{e}}\left(\mathrm{mg} \mathrm{dm}^{-3}\right)$

Figure 3: Adsorption isotherm for aniline on $1.4 \mathrm{Cu}-\mathrm{ZSM}-5\left(\square 6^{\circ} \mathrm{C}, \bullet 24^{\circ} \mathrm{C}\right)$.

Table 2: $\quad$ Langmuir constants for aniline adsorption on $1.4 \mathrm{Cu}-\mathrm{ZSM}-5$ zeolite at $6^{\circ} \mathrm{C}$ and $24^{\circ} \mathrm{C}$.

\begin{tabular}{ccccc}
\hline \multicolumn{1}{c}{ 1.4Cu-ZSM-5 } & \multicolumn{2}{c}{ Langmuir Constants } \\
\hline $\begin{array}{c}\text { Temp } \\
\left({ }^{\circ} \mathrm{C}\right)\end{array}$ & $\begin{array}{c}\mathrm{K}_{\mathrm{L}} \\
\left(\mathrm{dm}^{3} \mathrm{~g}^{-1}\right)\end{array}$ & $\begin{array}{c}\mathrm{A}_{\mathrm{L}} \\
\left(\mathrm{dm}^{3} \mathrm{mg}^{-1}\right)\end{array}$ & $\begin{array}{c}\mathrm{K}_{\mathrm{L}} / \mathrm{A}_{\mathrm{L}} \\
\left(\mathrm{mg} \mathrm{g}^{-1}\right)\end{array}$ & $\mathrm{R}^{2}$ \\
\hline 6 & 1.44 & 0.037 & 38.9 & 0.997 \\
24 & 1.47 & 0.035 & 41.8 & 0.997 \\
\hline
\end{tabular}

Both the Langmuir [14] and Freundlich [15] models, as defined below in Equations (1) and (2), respectively, were applied to the adsorption data.

$$
\begin{aligned}
& q_{e}=\frac{K_{L} C_{e}}{1+A_{L} C_{e}} \\
& q_{e}=K_{F} C^{1 / n}
\end{aligned}
$$

where $q_{e}$ is the amount of solute adsorbed per gram of adsorbent and $K_{L}$ and $A_{L}$ are Langmuir constants. A plot of $C_{e} / q_{e}$ versus $C_{e}$ from the linear form of Equation (1) was drawn to determine the values of $K_{L}$ (intercept) and $A_{L} / K_{L}$ (slope). Maximum uptake on the zeolite adsorbent surface was then obtained as $K_{L} / A_{L}$. The data in Table 2 indicate that the sorption of the aniline from aqueous solution onto the zeolite material showed good fit to the Langmuir model.

\subsection{Kinetics and thermodynamics of aniline adsorption}

Figure 3 suggests that temperature change from $6^{\circ} \mathrm{C}$ to $24^{\circ} \mathrm{C}$ has little impact on the aniline adsorption level. The results of the kinetic experiments undertaken on 1.4Cu-ZSM-5 are represented in Table 3. 
Table 3: Kinetic data displaying the equilibrium time required for aniline adsorption at $24^{\circ} \mathrm{C}$ onto $1.4 \mathrm{Cu}-\mathrm{ZSM}-5$.

\begin{tabular}{ccc}
\hline $\begin{array}{c}\text { Initial Aniline } \\
\text { Concentration } \\
\left(\mathrm{mg} \mathrm{dm}^{-3}\right)\end{array}$ & $\begin{array}{c}\text { Maximum } \\
\text { Adsorption Level } \\
\left(\mathrm{mg} \mathrm{g}^{-1}\right)\end{array}$ & $\begin{array}{c}\text { Time to Maximum } \\
\text { Adsorption } \\
(\text { Minutes })\end{array}$ \\
\hline 125 & 11 & 30 \\
250 & 23 & 30 \\
500 & 32 & 30 \\
\hline
\end{tabular}

The findings revealed that equilibrium aniline uptake generally occurred within approximately 30 minutes of contact time irrespective of the initial aniline concentration used in the kinetic study.

\subsection{Catalytic oxidation of adsorbed aniline}

Figure 4 illustrates the desorption profile for aniline over H-ZSM-5 and 1.4CuZSM-5 during catalytic oxidation. The H-ZSM-5 sample was used to assess the influence of copper loading on aniline oxidation. In the case of the H-Beta zeolite, unreacted aniline is clearly visible in the exhaust gases from the reactor. The presence of copper on the zeolite (1.4Cu-ZSM-5) considerably reduces the concentration of aniline in the exhaust gases indicating strong oxidation of the adsorbed aniline to breakdown products.

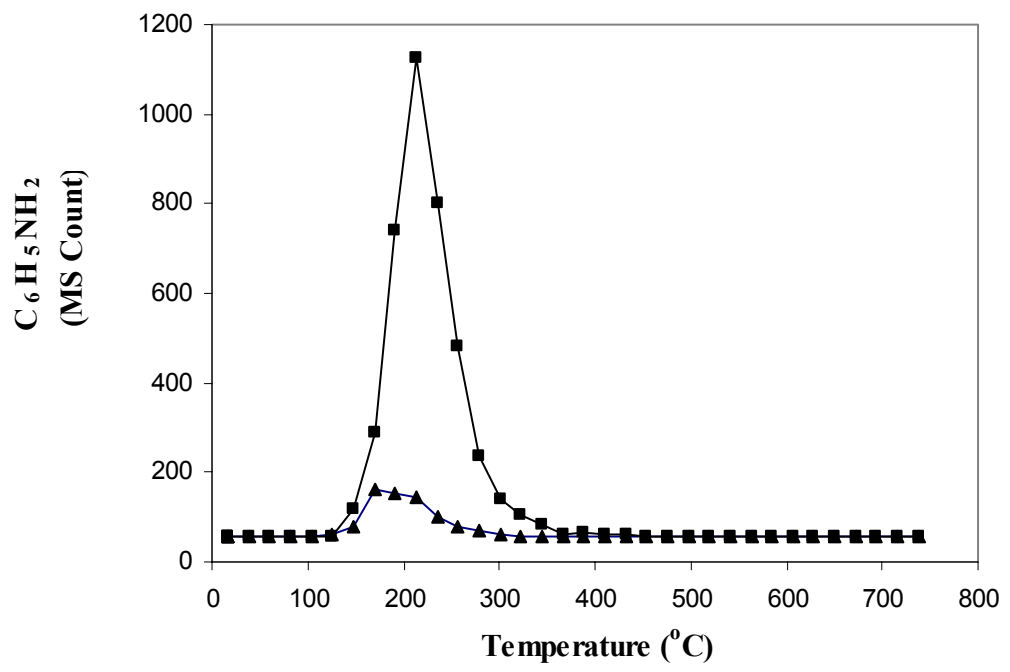

Figure 4: Comparison of the desorption of aniline on the ZSM-5 zeolites (100mg of zeolite sample containing $10.5 \mathrm{mg}$ aniline, $3 \% \mathrm{O}_{2} / \mathrm{He}$ gas flow, to $750^{\circ} \mathrm{C}$ at $\left.10^{\circ} \mathrm{C} / \mathrm{min}\right)(\boldsymbol{\nabla} \mathrm{H}-\mathrm{ZSM}-5, \boldsymbol{\Delta} 1.4 \mathrm{Cu}-\mathrm{ZSM}-5)$. 
The degradation of aniline sorbed on 1.4Cu-ZSM-5 should be accompanied by a corresponding increase in carbon dioxide level in the exhaust gases from the reactor as evidenced in figure 5. While aniline desorbs from the zeolite bed at $200^{\circ} \mathrm{C}$, subsequent conversion into carbon dioxide does not occur until temperatures higher than approximately $400^{\circ} \mathrm{C}$. Significantly, the $\mathrm{CO}_{2}$ profiles in figure 5 also show that the presence of copper loading on the $1.4 \mathrm{Cu}-\mathrm{ZSM}-5$ zeolite effectively reduces the temperature required for oxidation of the aniline as evidenced by the lower temperature emission of $\mathrm{CO}_{2}$. Preliminary work has also shown similar increases in nitrogen and water formation in the exhaust gases. Further work on the reproducibility of the $1.4 \mathrm{Cu}-\mathrm{ZSM}-5$ catalytic activity for aniline degradation over successive cycles is currently being researched.

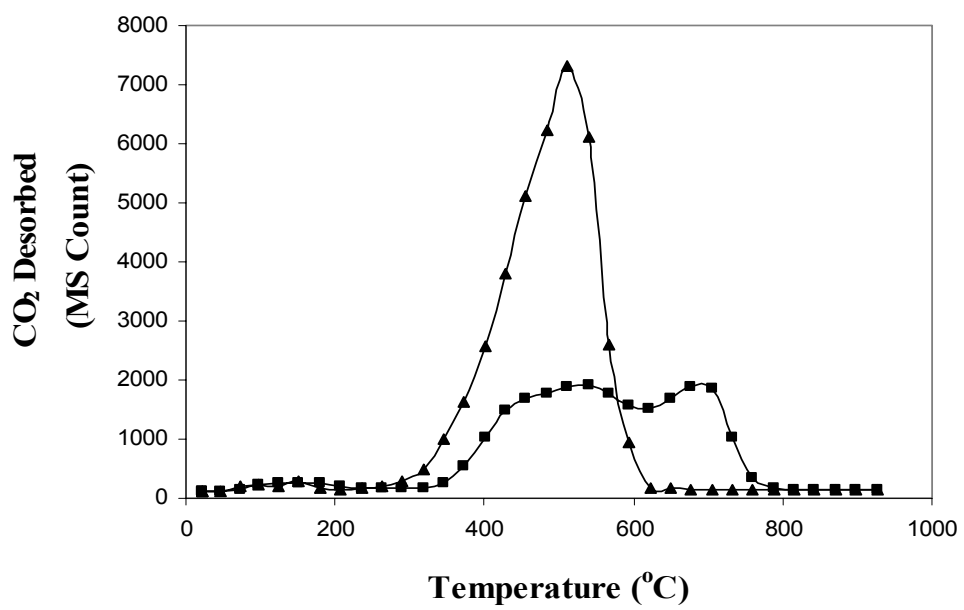

Figure 5: Comparison of the desorption of $\mathrm{CO}_{2}$ on the ZSM-5 zeolites (100mg of zeolite sample containing $10.5 \mathrm{mg}$ aniline, $3 \% \mathrm{O}_{2} / \mathrm{He}$ gas flow, to $750^{\circ} \mathrm{C}$ at $\left.10^{\circ} \mathrm{C} / \mathrm{min}\right)(\boldsymbol{\mathrm { H }}-\mathrm{ZSM}-5, \mathbf{\Delta} 1.4 \mathrm{Cu}-\mathrm{ZSM}-5)$.

\section{Conclusion}

A two-stage system was designed whereby initially the aniline was removed from solution by an adsorption step and subsequently the adsorbed aniline was catalytically oxidized to carbon dioxide, water and nitrogen with minor quantities of other gases. The 1.4Cu-ZSM-5 adsorption process (Step 1) has been shown to be effective with aniline uptake levels of $40 \mathrm{mg} \mathrm{g}^{-1}$ being achieved. The catalytic oxidation process (Step 2) has been shown to effectively destroy the aniline sorbed on $1.4 \mathrm{Cu}-\mathrm{ZSM}-5$. The system has shown considerable promise and further work is currently being carried out specifically to address a number of key issues including the suitability of the process for stripping other organic compounds, the potential selectivity towards specific organics, the mechanism by which the catalytic oxidation process occurs, potential de-activation of the 
1.4Cu-ZSM-5 adsorbent/catalyst, the emission of carbon dioxide and the physical development of a larger scale system.

\section{Acknowledgements}

The authors of this research work would like to acknowledge the funding and support of the Materials and Surface Science Institute at the University of Limerick, Ireland.

\section{References}

[1] Knighton, C.S., (Ed.), Water for People Water for Life - UN World Water Development Report, UNESCO Publishing, Paris, 2003

[2] Marcucci, M., Ciardelli, G., Matteucci, A., Ranieri, L. and Russo, M., Experimental Campaigns on Textile Wastewater for Reuse by Means of Different Membrane Processes, Desalination, 149, pp. 137-143, 2002.

[3] Hancock, F. E., Catalytic Strategies for Industrial Water Reuse, Catalysis Today, 53, pp. 3-9, 1999.

[4] Zbontar Zver, L. and Glavic, P., Water Minimization in Process Industries: Case Study in Beet Sugar Plant, Resources, Conservation and Recycling, 43, pp. 133 -145, 2005.

[5] Saha, N.K., Balakrishnan, M. and V.S. Batra, Improving Industrial Water Use: Case Study for an Indian Distillery, Resources, Conservation and Recycling, 43, pp. 163-174, 2005.

[6] Bastaki, A. and Nader, M., Performance of Advanced Methods for Treatment of Wastewater: UV/TiO2, RO and UF, Chemical Engineering and Processing, 43, pp. 935-940, 2004.

[7] Shu, H.T., Li, D., Scala, A.A. and Ma, Y.H., Adsorption of Small Organic Pollutants from Aqueous Streams by Aluminosilicate-Based Microporous Materials, Separation and Purification Technology, 11, pp. 27-36, 1997.

[8] Narita, E., Horiguchi, N. and Okabe, T., Adsorption of Phenols, Cresols and Benzyl Alcohol from Aqueous Solution by Silicalite, Chem. Lett., pp. $787,1985$.

[9] Khalid, M., Joly, G., Renaud, A. and Magnoux, P., Removal of Phenol from Water by Adsorption using Zeolites, Ind. Eng. Chem. Res. 43, pp. 5275, 2004.

[10] Lenihan, S. and Curtin, T., Copper Exchanged Beta Zeolites for the Catalytic Oxidation of Ammonia, Chem. Commun., pp. 1280-1281, 2003.

[11] Centi, G. and Perathoner, S., Recycle Rinse Water: Problems and Opportunities, Catalysis Today, 53, pp. 19-47, 1999.

[12] Iwamoto, M., Yahiro, H., Torikai, Y., Yoshioka, T. and Mizuno, N., Novel Preparation Method of Highly Copper Ion-Exchanged ZSM-5 Zeolites and their Catalytic Activities for NO Decomposition, Chemistry Letters, pp. 1967-1970, 1990. 
[13] Brunauer, S., Deming, L.S., Deming, W.E. and Teller, E., On A Theory of the Van der Waals Adsorption of Gases, J. Am. Chem. Soc., 62, pp. 17231732, 1940.

[14] Langmuir, I., The Adsorption of Gases on Plane Surfaces of Glass, Mica and Platinum, J. Am. Chem. Soc., 40, pp. 1361-1403, 1918.

[15] Freundlich, H.A., Uber die Adsorption in Losungen, Z. Phys. Chem., A 57, pp. 385, 1906. 